$22.4 \%$ in controls. The prevalence of HLA B7 was also higher in idiopathic haemochromatosis than in controls $(38.4 \% v 11.3 \%$ and $14.6 \%$ ).

An association between the haemochromatosis gene and the A3B7 haplotype has been seen in all series throughout the world. ${ }^{3}$ Associations with $\mathrm{A} 3 \mathrm{~B} 14,{ }^{38} \mathrm{~A} 11 \mathrm{~B} 35$ and $\mathrm{A} 11 \mathrm{~B} 5{ }^{3}{ }^{3} \mathrm{~A} \mathrm{~B}^{8}{ }^{8}$ and $\mathrm{A} 3 \mathrm{~B} 35^{\circ}$ were also observed in different countries.

The association with A3B7 was observed in five probands of our series. The A3 antigen showed linkage with other $B$, not B7, antigens in four probands. In five probands with A3B7 phenotype pedigree analysis showed that only four of five genotypes accorded with the proband's genotypes.

Our results agree with data reported from other countries; A3 is significantly more common on idiopathic haemochromatosis chromosomes regardless of the presence or absence of B7 or B14, and A3 (and to a lesser degree A11) is the independent idiopathic haemochromatosis allele marker. ${ }^{3}$

The number of heterozygotes, identified through pedigree studies, agrees with the expected prevalence according to published findings, ${ }^{10}$ the number of homozygotes, however, was small. The probability of finding HLA identical (homozygote) family members through pedigree studies is influenced by different factors: the recessive mode of inheritance, the gene prevalence in the population, and number of siblings in the family, etc.

The HLA identical, but disease free sibling, was a 40 year old women with regular menses. The transferrin saturation value and the serum ferritin concentration were normal. She may be an example of incomplete expressivity or recombination. ${ }^{24} \mathrm{~A}$ detailed investigation of DNA polymorphism would be required to explain this finding. Extended family and population studies are necessary in Hungary to establish the prevalence of the gene and the likely role of haplotypes other than A3B7.

1 Powel LW, Basset ML, Halliday JW. Hemochromatosis: 1980 update. Gastroenterology 1980;78:374-81.

2 Powel LW, Ferluga J, Halliday JW, Basset ML, KohonenCorish M, Serjeantson S. Genetic hemochromatosis and HLA linkage. Hum Genet 1987;77:55-6.

3 Simon M, Le Mignon L, Fauchet R, et al. A study of 609 HLA haplotypes marking for hemochromatosis gene: (1) Mapping of the gene near HLA-A locus and characters required to define a heterozygous population; and (2) Hypothesis concerning the underlying cause of association. Am J Hum Genet 1987;41:89-105.

4 Edwards CQ, Cartwright GE, Skolnick MH, Amos DB. Homozygosity for hemochromatosis: clinical manifestations. Ann Intern Med 1980;93:519-25.

5 Scheuer PJ, Williams R, Muir AR. Hepatic pathology in relatives of patients with hemochromatosis. J Patho relatives of patients with
Bacteriol 1962;84:53-64.

6 NIH NIAID Manual of tissue typing techniques 19761977. Washington DC: DHEW Publications (NIH) 1976: 75-545, 22-4.

7 Simon M, Fauchet R, Le Gall JY, Brissot P, Bourel $M$. Immunogenetics of idiopathic hemochromatosis and secondary iron overload. In: Nadir R Fareid, ed. Immunogenetics of endocrine Disorders. New York: Alan R Liss Inc, 1988:345-71.

8 Ritter B, Säfwenberg J, Olsson KS. HLA as a marker of the hemochromatosis gene in Sweden. Hum Genet 1984;68: 62-6.

9 Piperno A, Fargion S, Panajotopoulos N, Ninno E, Del Taddei MT, Fiorelli G. Idiopathic haemochromatosis and HLA antigens in Italy: is A3Bw35 HLA haplotype a marker for idiopathic haemochromatosis gene in north marker for idiopathic haemochromatosis

10 Cartwright GE, Edwards CQ, Kravitz K, et al. Hereditary hemochromatosis. Phenotypic expression of the disease. N Engl J Med 1979;301:175-9.

\title{
Cytogenetic analysis of a granulocytic sarcoma in a patient without systemic leukaemia
}

\author{
L R Adam, B Angus, P Carey, E V Davison
}

Department of

Human Genetics,

University of

Newcastle upon Tyne

NE2 4AA

L R Adam

Department of

Pathology, University

of Newcastle upon

Tyne

B Angus

Department of

Haematology, Royal

Victoria Infirmary,

Newcastle upon Tyne

P Carey

Department of

Clinical Cytogenetics,

Birmingham

Maternity Hospital

E V Davison

Correspondence to:

L R Adam

Accepted for publication

26 July 1990

\begin{abstract}
Granulocytic sarcoma is a rare complication of leukaemia. Occasionally it presents before the development of systemic leukaemia when diagnosis may be difficult. A case of granulocytic sarcoma occurring in a patient with no overt evidence of leukaemia, but in whom cytogenetic analysis of the bone marrow showed a clonal $t(12 ; 13)$ translocation, is reported. Cytogenetic analysis of tissues in this disease may indicate evidence of systemic disease before overt morphological changes.
\end{abstract}

Granulocytic sarcoma is a rare tumour, defined as a "localised tumour mass composed of immature cells of the granulocytic series". The most common sites of presentation are bone, periosteum, soft tissue, lymph node and skin. The tumour may develop during the course of acute myeloblastic leukaemia (AML), chronic myeloid leukaemia (CML), or other myelodysplastic disorder. Alternatively, the tumour precedes leukaemia by some months. ${ }^{2}$ When granulocytic sarcoma presents without blood or bone marrow manifestations of leukaemia, the diagnosis may be missed. ${ }^{3}$ Histological diagnosis can be difficult and many patients are initially diagnosed as having high grade lymphoma. ${ }^{4-6}$ Often the first indication of misdiagnosis is the lack of response to treatment.

\section{Case report}

A 52 year old man presented with a rapidly enlarging chest wall mass, initially thought to be a high grade non-Hodgkin's lymphoma. Staging investigations showed no evidence of disease elsewhere and he was treated with 


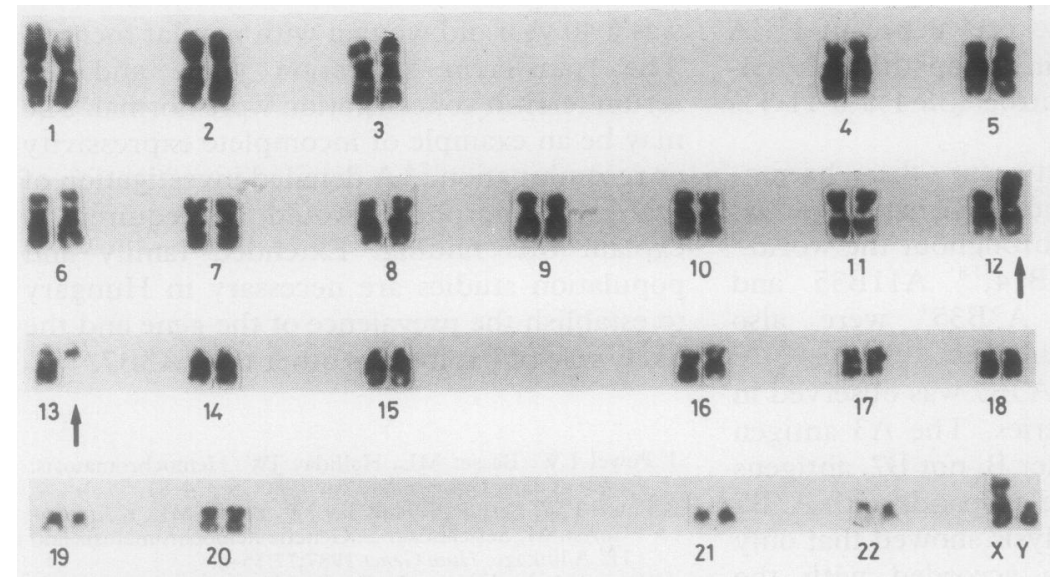

Karyotype of abnormal cell line: $46, X Y, t(12 ; 13)(p 12 ; q 12)$

three cycles of chemotherapy (cyclophosphamide, adriamycin, vincristine and prednisolone). After a partial response the tumour continued to grow and a second biopsy was performed. This time some of the tumour cells showed cytoplasmic granularity, suggestive of myeloid differentiation; chloroacetate esterase (CAE) and antilysozyme positivity supported the diagnosis of granulocytic sarcoma. Review and further staining of the first biopsy specimen showed similar findings and the initial diagnosis was revised. The only haematological abnormality, found in the peripheral blood at presentation and at the time of the second biopsy, was hyposegmentation of the nucleus in a proportion of the neutrophils (pseudoPelger-Huet anomaly). The peripheral blood cell counts were normal and there were no other dysplastic features. Bone marrow specimens were obtained at presentation and at the time of the second biopsy and showed no other features of dysplasia, no excess of blast cells, and no evidence of other infiltration. Cytogenetic analysis of the second tumour biopsy specimen showed an apparently normal 46, XY karyotype, but simultaneous analysis of bone marrow cells showed an abnormal $46, \mathrm{XY} / 46, \mathrm{XY}, \mathrm{t}(12 ; 13)$ (p12;q12) karyotype (figure). In view of the persisting tumour and the cytogenetic abnormality in the marrow, the patient was given local radiotherapy followed by further chemotherapy (daunorubicin, cytosine, and thioguanine). Unfortunately, he died shortly afterwards following a cerebral haemorrhage.

\section{Discussion}

This patient remained free of systemic leukaemia until his death nine months after granulocytic sarcoma was diagnosed. The only signs of disease were the presence of the pseudo-Pelger-Huet anomaly in peripheral blood and the chromosome translocation in bone marrow. Unexpectedly, the translocation was not observed in the tumour cells. This probably reflects our failure to culture malignant cells from the tumour sample, and suggests that the karyotypically normal cells were derived from normal tissue surrounding the tumour.

Granulocytic sarcoma is thought to occur more frequently in association with myeloid leukaemias showing the $t(8 ; 21)$ translocation.? It may be that associations with rarer specific chromosome abnormalities will emerge as more data accumulate. Russell et al report a similar case of granulocytic sarcoma preceding acute myelomonocytic leukaemia (AMML), in which cytogenetic analysis of marrow showed an abnormal cell line, with a pericentric inversion of chromosome 16, associated with myeloblastic leukaemia (AML) FAB type $\mathrm{M}_{4} \mathrm{Eo}^{8}$ The authors suggest that progression of this tumour to AML $M_{4}$ Eo is a recurring association and, if treated aggressively with the appropriate chemotherapy when the tumour is diagnosed, carries a more favourable prognosis.

Although the $t(12 ; 13)(p 12 ; q 12)$ abnormality we describe is not recognised as a specific marker in malignancy, we have recently observed two other cases in which rearrangements involving $12 \mathrm{p} 12$ have been the sole abnormality. In the first, a patient with AMML, we found an identical $t(12 ; 13)(p 12$; q12) translocation, and in the second, a child with $A M L$, we reported a similar $t(12 ; 13)$ (p12;q14) abnormality. The translocations in all three cases seem to be unbalanced with partial deletion of the short arm of chromosome 12 (12p12-pter). The histology and cytochemistry of these cases suggest no common features except that in each case the disease is of myeloid origin. Abnormalities involving $12 \mathrm{p} 12$ have frequently been reported, usually in myelodysplastic syndromes and acute non-lymphocytic leukaemia, and most commonly in secondary disorders when additional chromosome changes are also present. Reports suggest that partial deletion of $12 p$ is non-randomly associated with secondary leukaemia, rather like monosomy 7 or 7q-. ${ }^{9}$

Monitoring cytogenetic changes in bone marrow in patients likely to develop systemic disease is helpful in the early detection and treatment of leukaemic transformation.

We thank Dr R Finney, North Tees General Hospital, for permission to report this case, and the North of England Childrens' Cancer Research Fund for their financial support.

1 Neiman RS, Barcos M, Berard C, et al. Granulocytic sarcoma: a clinicopathologic study of 61 biopsied cases. Cancer 1981;48:1426-37.

2 Meis JM, Butler JJ, Osborne BM, Manning JT. Granulocytic sarcoma in non-leukemic patients. Cancer 1986;58 2697-709.

3 Comings DE, Fayen AW, Carter P. Myeloblastoma preceding blood and marrow evidence of acute leukemia. Cancer 1965;18:253-8.

4 McCarty KS, Wortman J, Daly J, Rundles RW, Hanker JS. Chloroma (granulocytic sarcoma) without evidence of leukemia: facilitated light microscope diagnosis. Blood 1980;56:104-8.

5 McCallum PK, Newbould MJ, Sambrook PS, Burton IE. Extramedullary haemopoietic tumours complicating polycythaemia vera. J Clin Pathol 1988;41:609-14.

6 Mansi L, Selby PJ, Carter RL, Powles RL, McElwain TJ. Granulocytic sarcoma: a diagnosis to be considered in unusual lymphoma syndromes. Postgrad Med J 1987, 63:447-9.

7 Swirsky DM, Li YS, Matthews JG, Flemans RJ, Rees JKH, Hayhoe FGJ. 8;21 translocation in acute granulocytic eukaemia: cytological, cytochemical and clinical features. Br J Haematol 1984;56:199-213.

8 Russell SJ, Giles FJ, Thompson DS, Scanlon DJ, Walker H, Richards JDM. Granulocytic sarcoma of the small intenstine preceding acute myelomonocytic leukemia with abnormal eosinophils and inv(16). Cancer Genet Cytogenet 1988;35:231-5.

9 Berger R, Bernheim A, Le Coniat M, et al. Abnormalities of the short arm of chromosome 12 in acute nonlymphocytic leukemia and dysmyelopoietic syndrome. Cancer Genet Cytogenet 1986;19:281-9. 